\title{
ПАРТНЕРСТВО УНИВЕРСИТЕТОВ В РОССИЙСКОЙ ФЕДЕРАЦИИ: ПРАВОВОЕ РЕГУЛИРОВАНИЕ, ТИПОЛОГИЯ И ВЫЗОВЫ ВРЕМЕНИ *
}

\author{
(c) 2020 Щукина Татьяна Владимировна \\ доктор юридических наук, доцент, заведующая кафедрой прикладного права \\ Российский Технологический Университет - МИРЭА, Россия, Москва
}

Предметом настоящей статьи выступает исследование теоретических и практических представлений о партнерстве университетов как одной из форм, способствующих развитию экспорта высшего образования за рубеж; рассмотрение новых тенденций создания партнерств университетов в условиях стратегического развития Российской Федерации. Тема статьи отражает характеристику отношения внутренней среды к экспорту образования, к университетским консорциумам. Целью настоящей статьи является разработка и обоснование типологии университетских партнерств, особенности их создания и функционирования, выявление специфики объединения университетов с некоммерческими организациями и бизнес партнерами. Методологию данной работы составили сравнительный, формально-юридический, аналитический методы. Результаты работы - это формулирование особенностей университетских партнерств в условиях снижения темпов экспорта российского высшего образования за рубеж. Область применения результатов работы включает в себя систему управления высшим образованием. Выводы исследования могут быть использованы для дальнейшего совершенствования правовой регламентации и практики организации международного сотрудничества в сфере высшего образования.

Ключевые слова: экспорт высшего образования, нормативное правовое регулирование экспорта высшего образования, университетские партнерства.

Формирование и развитие партнерских отношений в системе высшего образования свидетельствует о том, что кооперация среди образовательных организаций предоставляет им возможность более эффективно реализовывать собственные университетские стратегии и привлекать наибольшее количество качественных ресурсов. Зарубежными учеными отмечается, что «стратегии интеграции включают в себя формирование партнерств с использованием ресурсов двойного назначения. Использование ресурсов «двойного назначения» - это продолжение использования имеющихся ресурсов для существующих целей, но добавление к ним еще и цели интернационализации. Двойное назначение ресурсов, по своей сути, является «интегративным». Ресурсы бывают разных форм деньги, а также существующие преподаватели и персонал, академические программы и подразделения поддержки и обслуживания в рамках всего учреждения. Благодаря двойному назначению ресурсов интернационализация дает ориентацию и возможность повысить качество и актуальность основных миссий высшего образования, тем самым также обеспечивая расширенные учебные и исследовательские платформы» [1]. Создание разнообразных университетских партнерств помогает не только продвижению интернационализации в сложных современных условиях, но и обеспечивает определенную стабильность для университетов как участников рынка образования.

В докладе ЮНЕСКО по науке: По пути к 2030 году указывается, «что университеты сами по себе стали глобальными игроками на рынке образования. Они все сильнее конкурируют друг с другом в привлечении средств, профессоров и талантливых студентов. Репутация университета определяется на глобальном уровне. Эта тенденция будет усиливаться по мере цифровой революции, которая дает университетам мирового класса все большее присутствие в мире посредством онлайновых курсов» [2]. Патрик Эбишер раскрывает глобальную роль университетов, значение университетских партнерств и их ответы на новые вызовы: «В последние

\footnotetext{
* Статья подготовлена в рамках гранта РФФИ 19-011-00959 «Моделирование экспорта высшего образования в рамках новых стратегий публичного управления в Российской Федерации» 2019-2021 г.г.
} 
годы правилом стало дистанционное сотрудничество: ученые теперь живут в сверхсвязанном мире. Создание и передача научных знаний критическое условие для обеспечения устойчивого социально- экономического благополучия и интеграции в мировую экономик. Развитие инноваций является необходимой ролью университетов; инновации (или передача технологий) должны стать важной миссией обучения и исследований. Партнерство университетов в совместной работе, переоценка, интеграция, смешанные и сертифицируемые занятия станут возможны во всем мире. Университеты будущего будут глобальными и многоуровневыми предприятиями, с живым кампусом, несколькими отделениями у стратегических партнеров и глобальным виртуальным онлайновым присутствием» [3].

Происходящие в мире трансформации обуславливают появление новых форм университетских партнерств и в России. Этому процессу способствует политико-государственная стратегия в области высшего образования. Программа стратегического академического лидерства (программа «Приоритет 2030») предусматривает поддержку реализации образовательных программ высшего образования в сетевой форме, осуществление творческих и социальногуманитарных проектов с участием образовательных организаций, научных организаций и других организаций, в том числе организаций реального сектора экономики и социальной сферы. Дополнительная поддержка по данной программе также будет оказываться образовательным организациям, которые включат в свои программы развития мероприятия по объединению с другими образовательными и научными организациями независимо от их ведомственной подчиненности на основании соглашений о взаимодействии без образования юридического лица [4].

Университетские партнерства представляют собой разнородные образования различных субъектов связанных с образовательной деятельностью (университеты), и связанных с ней: государственные корпорации, коммерческие компании, некоммерческие организации, благотворительные фонды. Подобные сетевые партнерства действуют на основе взаимных соглашений сотрудничестве для достижения взаимовыгодных целей и задач, косвенно или прямо учитывающих национальные политические приоритеты. Конечно, для самих партнерств экономическая выгода и дополнительные источники финансирования от совместных проектов являются одной из первостепенных задач.

По мнению, Бельски Л. «Глобальная задача всех государств - повышение доступности высшего образования во всем мире, и университеты могут стать эпицентром реформ образования. С помощью технологий они могут объединять усилия и создать общую обучающую экосистему, а также дополнить свои собственные программы лучшими курсами от других учебных заведений» [5]. Нельзя не учитывать и исследовательскую заинтересованность участников в партнерстве, так как эта компонента выступает одной из главных характеристик создаваемых партнерств. Без творчества, креативного подхода к созданию образовательных и инновационных коммерческих продуктов невозможно занять лидирующие позиции в любом сегменте экономических отношений.

С 13 ноября 2019 года по 13 декабря 2019 года был проведен опрос на тему «Экспорт высшего образования» и охвачено 118 человек преподавателей и студентов из 26 субъектов Российской Федерации по вопросам, касающимся сущности экспорта высшего образования за рубеж и их отношения к подобному процессу. Перед опрошенными лицами было поставлено более 20 вопросов, некоторые из которых касались университетской мобильности. Это: «В каких форматах экспорта высшего образования за рубеж Вы приняли бы участие?», «Каков должен быть минимальный срок реализации проекта экспорта высшего образования за рубеж?», «Каков должен быть максимальный срок реализации проекта экспорта высшего образования за рубеж?». Преподаватели российских вузов готовы к реализации условий университетской мобильности в рамках деятельности университетских партнерств, включая и длительные сроки действия подобных проектов. Но сроком эффективного функционирования проекта, они считают -5 лет. Таким образом, через пять лет, по мнению респондентов, стоит менять концепции любого проекта мобильности и партнерства.

Проведенный опрос с 13 ноября 2019 года по 13 декабря 2019 года на тему «Экспорт высшего образования» показал, что преподаватели российских вузов готовы к реализации условий университетской мобильности в рамках деятельности университетских партнерств. Перед 
опрошенными был поставлен вопрос: «В каких форматах экспорта высшего образования за рубеж Вы приняли бы участие?» В качестве вариантов ответа предложены: «Летняя или зимняя международная Школа», «Обучение или разработка образовательных программ бакалавриата, магистратуры с двойными дипломами», «Обучение или разработка образовательной программы магистратуры и аспирантуры с присвоением ученой степени $\mathrm{PhD»,} \mathrm{«Участие} \mathrm{в} \mathrm{программах}$ обмена студентами, преподавателями», а также возможность сформулировать собственный вариант. Допускалось несколько вариантов ответа. Результаты представлены на рисунке 1.

Можно отметить, что опрошенные признавали приемлемыми и (или) приоритетными для себя все предложенные формы экспорта высшего образования за рубеж. Предпочтение отдается программам обмена и международным школам. Однако и иные формы не вызывают возражений. Относительно сроков реализации проектов экспорта образования опрошенные высказали довольно широкий спектр мнений. Так, на вопрос: «Каков должен быть минимальный срок реализации проекта экспорта высшего образования за рубеж?» были представлены ответы от «1 неделя» до «10 лет» (см., рисунок 2). Более того, неоднократно отмечалось, что минимальный срок вообще не следует определять, поскольку он обусловлен особенностями конкретного проекта. Наиболее популярные ответы с довольно близкими показателями $-1,2,3$ и 5 лет.

На вопрос: «Каков должен быть максимальный срок реализации проекта экспорта высшего образования за рубеж?» были представлены ответы от «1 месяц» до «50 лет» (см., рисунок 3).

\section{В каких форматах экспорта высшего образования за рубеж Вы приняли бы участие?}

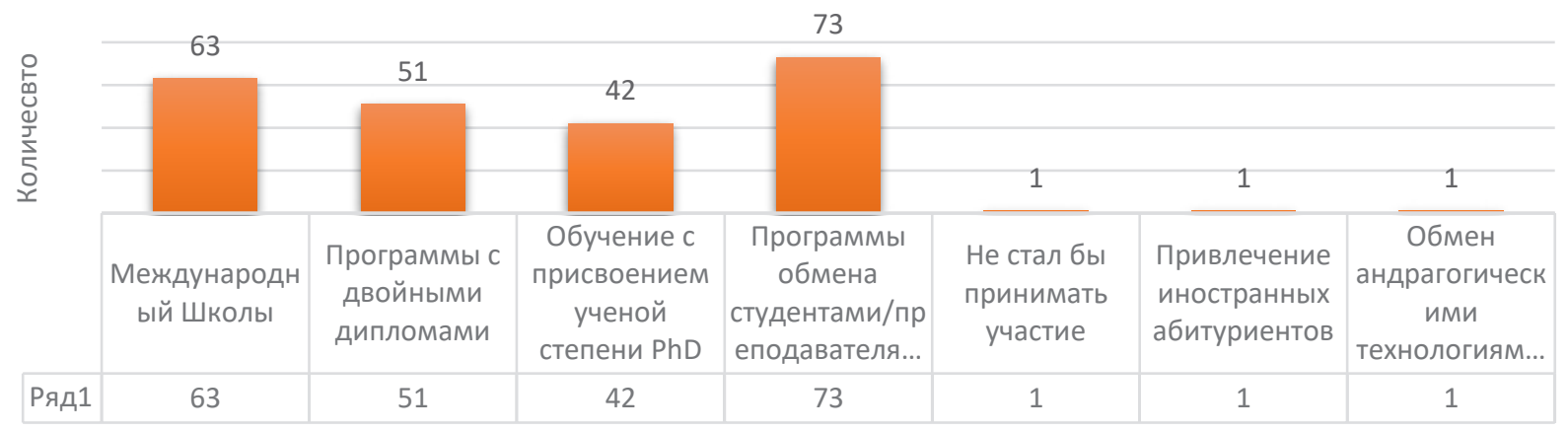

Puc. 1. Результаты опроса о формах мобильности в рамках деятельности университетских партнерств

\section{Каков должен быть минимальный срок реализации проекта экспорта высшего образования за рубеж?}

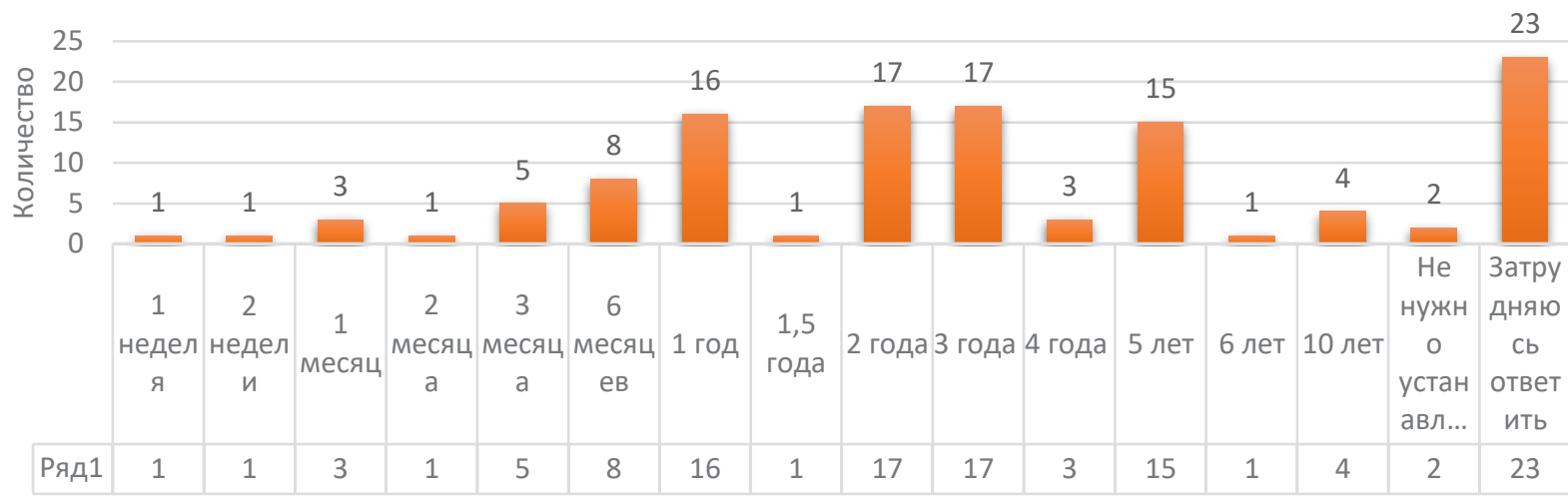

Рuc. 2. Результаты опроса о минимальных сроках университетской мобильности 


\section{Каков должен быть максимальный срок реализации проекта экспорта высшего образования за рубеж?}

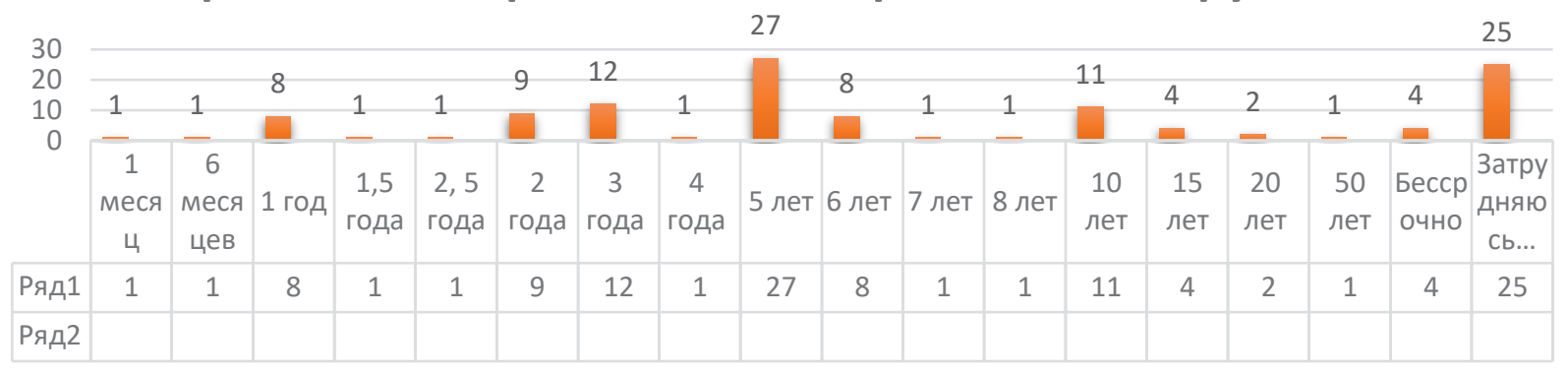

Puc. 3. Результаты опроса о максимальных сроках университетской мобильности

Кроме того, так же, как и на вопрос о минимальном сроке, ряд респондентов указали, что срок вообще не следует определять, поскольку он обусловлен особенностями конкретного проекта. Наиболее популярный ответ -5 лет.

В итоге, авторы опроса поняли, что преподаватели российских вузов считают эффективным сроком функционирования программ университетской мобильности - 5 лет. Таким образом, через пять лет, по мнению респондентов, стоит менять концепции любого проекта мобильности и партнерства.

Представим свою позицию относительно классификации университетских партнерств. Следует выделить четыре крупных группы партнерств, которые объединяются по статусу участника и целям их взаимодействия.

Форма «Университетские партнерства». Наиболее распространенный вид университетских партнерств, «характеризующийся разнообразием институций, форматов и направлений сотрудничества, целевой аудитории и видов мобильности. Подобный тип партнерства еще называется стратегическим партнерством» [6].

Форма «Образовательно-некоммерческие nартнерства» - это гибкий, творческий формат сотрудничества между университетами и некоммерческими организациями. Один из видов подобной кооперации является взаимодействие университетов с различными фондами: Благотворительный фонд В.Потанина, DAAD и другими. В данном случае фонды финансируют программы мобильности, интернационализации, развития преподавания [7]. Возможно партнерство университетов с другими видами некоммерческих организаций с целью реализации образовательных и научно- исследовательских проектов и программ: АСИ, Точки Кипения, Агентство технологий развития частно-государственного партнерства и др. Подобный вариант реализован путем подписания 22 июля 2020 года в Сколтехе меморандума о партнерстве со стороны руководителей 33 университетов России совместно с Агентством стратегических инициатив (АСИ), Платформой Национальной технологической инициативы (НТИ) и Университетом НТИ «20.35» [8]. Отметим, что «значительно труднее идет кооперация университетов со слабо структурированными представителями гражданского общества (населением, активистами, небольшими некоммерческими организациями)» [9].

Форма «Образовательно-коммерческие партнерства». Бизнес-партнерами могут выступать различные компании, корпорации, промышленные предприятия. Многие учебные заведения сотрудничают с мировыми гигантами: Facebook, Samsung, IBM, Apple, Google. В свою очередь, «компании расширяют поле деятельности, упрочивают свое положение на рынке и делают выгодные инвестиции, помогают патентовать инновационные продукты, продвигать их на рынке. Учебные заведения обретают особый статус» [10]. «Зарубежные университеты стали реализовывать подобные проекты в 2000-х годах. Например, компания Google объединила 25 общественных колледжей США, Юго-Восточного университета и Иллинойского университета в Спрингфилде под специализированную сертификатную программу в области компьютерных наук и IT; с Мюнхенским техническим университетом» [11]. Российские вузы также начинают сотрудничать с этими мировыми компаниями, «так Пермский государственный университет 
подписал соглашение о сотрудничестве с Bastille (Бастил) и Fish \& Richardson. По условиям договора Fish \& Richardson (представление интересов Google Inc. и Apple) осуществит международное патентованием разработок университета, а Bastille их коммерциализацией за рубежом» [12]. «Активно мировые компании сотрудничают с университетами и при проведении летних и зимних международных школ (Samsung и НИУ ВШЭ). Хотя определенное недоверие у коммерческих предприятий к научно-исследовательскому потенциалу вузов на постсоветском пространстве еще сохраняется. И кооперативное сотрудничество происходит на уровне крупных фирм и крупных университетов, в кооперативной деятельности слабо задействованы средние и малые предприятия и организации» [13]. Относительно классификации партнерств в рамках «Образовательно-коммерческие партнерства» выделяется множество критериев, видов моделей, таких как функциональная, мультидивизиональная, матричная, холдинговая модели [14].

Форма «Образовательно-научные цеентры мирового уровня». Роль университетов как драйверов кооперации субъектов негосударственного сектора и бизнеса велика. «Основу сектора образования, традиционно отвечающего за развитие человеческого потенциала, составляют университеты, которые объединяют научные исследования, создание и развитие инноваций» [15]. Мировой опыт показывает, что университеты играют разнообразную и зачастую ключевую роль в инновационной национальной системе, а также в создании и развитии человеческого потенциала, НИОКР и развитии инноваций [16].

В целях совершенствования функционирования университетов как научных и образовательных площадок в настоящее время и до 2024 года реализуется Национальный проект «Наука». «Согласно указу Президента РФ от 7 мая 2018 г. № 204 «О национальных целях и стратегических задачах развития Российской Федерации на период до 2024 года» в сфере науки обеспечиваются следующие цели и целевые показатели: 1) обеспечение привлекательности работы в РФ для российских и зарубежных ведущих ученых, молодых перспективных исследователей; 2) опережающее увеличение внутренних затрат на научные исследования и разработки за счет всех источников (по сравнению с ростом валового внутреннего продукта страны)» [17]. Главным стратегическим направлением в области науки выступает формирование целостной системы подготовки и профессионального роста научных и научно-педагогических кадров, обеспечивающей условия для осуществления молодыми учеными научных исследований и разработок, создания научных лабораторий и конкурентоспособных коллективов [18].

Сара Гури-Розенблит утверждает, что существуют случаи, когда высшие учебные заведения в стране и ее правительство решают проводить совместную стратегию по повышению престижа национальной системы высшего образования [19]. В Российской Федерации сеть ведущих российских университетов, Правительство РФ и крупные промышленные предприятия регионов объединяют свои усилия для создания научнообразовательных центров мирового уровня, действующих в рамках Национального проекта «Наука». «НОЦ - это объединение потенциалов ведущих научных и образовательных организаций высшего образования с организациями реального сектора экономики, проводящие научные исследования и разработки мирового уровня, результатом которых является получение новых конкурентоспособных технологий и продуктов и их коммерциализация, осуществляющие подготовку кадров для решения крупных научно-технологических задач по приоритетам научно-технологического развития Российской Федерации. НОЦ может быть межрегиональным» [20]. «На реализацию НОЦ из бюджета предполагается выделение 8621,0 млн. рублей. В 2019 году появилось пять таких центров в России: НОЦ «Кузбасс» (Кемеровская область), Западно-Сибирский межрегиональный НОЦ (Тюменская область), Пермский НОЦ «Рациональное недропользование» (Пермский край), НОЦ «Техноплатформа 2035» (Нижегородская область), НОЦ «Инновационные решения в АПК» (Белгородская область)» [21].

В итоге, партнерства вузов, компаний и некоммерческих организаций создадут на территории своей деятельности: во-первых, эффективные кластеры науки, образования, культуры, некоммерческого сектора, кластеры экономического развития и благополучия, мощную партнерскую сеть; во-вторых, трендовые социальные проекты, социальные мероприятия, лаборатории подготовки кадров и многое другое [22]. 


\section{Библиографический список}

1. John K Hudzik (2020), How to strengthen internationalisation post-COVID-19, available at: https://www. universityworldnews.com/post.php? story=20200605072319401 (accessed 6 June 2020)

2. UNESCO: Science Report Towards 2030, 2015. UNESCO: Science Report Towards 2030 (2015), Foreword by Irina Bokova, Director-General of UNESCO, UNESCO Publishing

3. Там же.

4. Распоряжение Правительства Российской Федерации от 31.12.2020 № 3607-p. Режим доступа: URL: http:// publication.pravo.gov.ru/Document/View /0001202101050007?index $=0$

5. Belsky, L. (2019), « How technology will change higher education», available at: https://www.vedomosti.ru/ management/articles/2019/12/11/818499-tehn ologii-izmenyat (accessed 11 December 2019)

6. Vatolkina, N., Fedotkina, O. (2018), «University’s International Strategic Partnership: Interaction Models», Higher education in Russia, Vol. 27, No. 6, pp. 113-119.

7. Guri-Rosenblit, S. (2015), «Internationalization of Higher Education: Navigating Between Contrasting Trends», In Curaj A. et al (Ed.), The European Higher Education Area, Springer Link, pp. 13-26, available at: https://ink. springer.com/ chapter/ 10.1007/978-3-319-20877-0_2

8. АСИ и 33 российских вуза подписали меморандум о партнерстве. Режим доступа: URL: https://news. myseldon.com/ru/news/index/213721148

9. Golubev, S.V., Novikova, T.G., Svetenko, T.V. (2011), University as a socially responsible partner of the territory: based on the materials of the University and Community project, New Eurasia Foundation, Moscow.

10. Stefanovich, M. (2019), «Foreign universities that collaborate with Apple, Google and other companies: why you should pay attention to foreign universities that collaborate with cool companies?», available at: https:// www. hotcourses.ru/ study-abroad-info/choosing-a-university/foreign-univer sities partnering -with-famouscompanies/ (accessed 25 January 2019).

11. Там же.

12. «PSNIU will cooperate with a partner Google и Apple» (2019), available at: https://perm.bezformata.com/listnews/ pgniu-budet-sotrudnichat-s-partnerom/1 628639/ (accessed 11 January 2019).

13. Ibyzhanova, A., Tarshilova L. (2015), «Modeling the impact of scientific and technical partnerships on the results of university activities», Basic Research, 2015, No. 4, pp. 203-207.

14. The manual on the interaction of universities and industrial enterprises (2015), available at: http://irdclub.ru/ materials (accessed 25 January 2015).

15. Kolomytseva, O., Pavlovska, A. (2020), «The role of Universities in the National Innovation System», Baltic Journal of Economic Studies, Vol. 6, No. 1, pp. 51-58.

16. Там же.

17. Паспорт национального проекта «Наука», утвержден президиумом Совета при Президенте Российской Федерации по стратегическому развитию и национальным проектам (протокол от 24 декабря 2018 г. № 16). Режим доступа: URL: https://internet.garant.ru/\#/document/72192484/paragraph

18. Там же.

19. Guri-Rosenblit, S. (2015), «Internationalization of Higher Education: Navigating Between Contrasting Trends», In Curaj A. et al (Ed.), The European Higher Education Area, Springer Link, pp. 13-26, available at: https://ink. springer.com/ chapter/ 10.1007/978-3-319-20877-0_2

20. О мерах государственной поддержки научно-образовательных центров мирового уровня на основе интеграции образовательных организаций высшего образования и научных организаций и их кооперации с организациями, действующими в реальном секторе экономики: постановление Правительства Российской Федерации от 30 апреля 2019 г. № 537. Режим доступа: URL: http://static.government.ru/media/files/LVFOfZn xUTjCwr1r6Cpr5Ne6mpADNrV5. pdf

21. Захарова В.В. Научно-образовательный центр как инструмент развития неоиндустриальной специализации регионов России. Режим доступа: URL: https://creativeconomy.ru/lib/109328

22. Shchukina, T.V. (2019), «Export of Russian Higher Education Abroad: Legal Regulation and Strategic Development Goals», Economics and Law, No.10 (136), pp. 29-35. 